\title{
Neural Dynamics Associated with Semantic and Episodic Memory for Faces: Evidence from Multiple Frequency Bands
}

\author{
Elana Zion-Golumbic ${ }^{1}$, Marta Kutas ${ }^{2}$, and Shlomo Bentin ${ }^{1}$
}

\begin{abstract}
Prior semantic knowledge facilitates episodic recognition memory for faces. To examine the neural manifestation of the interplay between semantic and episodic memory, we investigated neuroelectric dynamics during the creation (study) and the retrieval (test) of episodic memories for famous and nonfamous faces. Episodic memory effects were evident in several EEG frequency bands: theta (4-8 Hz), alpha (9-13 Hz), and gamma (40-100 Hz). Activity in these bands was differentially modulated by preexisting semantic knowledge and by episodic memory, implicating their different functional roles in memory. More specifically, theta activity and alpha suppression were larger for old compared to new faces at test regardless of fame, but were both larger for famous faces during
\end{abstract}

\section{INTRODUCTION}

Face recognition is a commonplace act that all humans perform daily. It is an essential part of effective social interactions, which rely on the ability to learn new faces, to associate them with contextual information while storing them in memory and, when appropriate, to correctly retrieve this knowledge from memory. As individuals develop personal relationships, new episodic representations are established in long-term memory, which are integrated with, and enriched by semantic knowledge. This then raises the question of what role prior semantic knowledge might play in the creation and/or retrieval of new episodic traces for faces, and what type of brain dynamics may mediate this cognitive interplay.

Neuropsychological and brain imaging studies have contributed considerably to our understanding of the brain areas involved in episodic and semantic memory generally and for face processing in particular (e.g., Gobbini \& Haxby, 2006; Haxby, Hoffman, \& Gobbini, 2000; GrillSpector et al., 1999). These studies have suggested that recognition of familiar or known faces (i.e., those associated with semantic information) involves different neural mech-

\footnotetext{
${ }^{1}$ The Hebrew University of Jerusalem, Jerusalem, Israel, ${ }^{2}$ University of California San Diego, La Jolla
}

study. This pattern of selective semantic effects suggests that the theta and alpha responses, which are primarily associated with episodic memory, reflect utilization of semantic information only when it is beneficial for task performance. In contrast, gamma activity decreased between the first (study) and second (test) presentation of a face, but overall was larger for famous than nonfamous faces. Hence, the gamma rhythm seems to be primarily related to activation of preexisting neural representations that may contribute to the formation of new episodic traces. Taken together, these data provide new insights into the complex interaction between semantic and episodic memory for faces and the neural dynamics associated with mnemonic processes.

anisms than those involved in the recognition of newly learned, unfamiliar, relatively unknown faces (Leube, Erb, Grodd, Bartels, \& Kircher, 2003; Leveroni et al., 2000). Nonetheless, remarkably little is known about the neural dynamics leading to and accompanying successful episodic memory encoding and retrieval, and whether, and if so how, the neural dynamics associated with these processes are influenced by semantic knowledge. Due to its exquisite temporal resolution, the electroencephalogram (EEG) can provide a good measure of neural dynamics.

Over the last decade, neural oscillations in multiple frequency bands have been implicated in coordinating the precise timing of neuronal activity (Fries, Nikolić, \& Singer, 2007; Jacobs, Kahana, Ekstrom, \& Fried, 2007; Fries, 2005), and facilitating cognitive processes such as perception, attention, long-term coding, and retrieval of information (Jensen, Kaiser, \& Lachaux, 2007; Buzsáki, 2005; Buzsáki \& Draguhn, 2004; Engel, Fries, \& Singer, 2001; Singer \& Gray, 1995). With regard to human memory, investigations using EEG, MEG, and intracranial recordings have revealed modulations of oscillatory activity in the theta $(4-8 \mathrm{~Hz})$, alpha $(9-13 \mathrm{~Hz})$, and high-gamma $(>40 \mathrm{~Hz})$ frequency bands during successful episodic encoding and retrieval. Many of these studies used a classic memory recognition paradigm in which participants first learn a series of items and are subsequently tested for recognition of these (old) items, interspersed among new ones. 
The primary EEG rhythm associated with memory is theta-the dominant rhythm in hippocampus (Buzsáki, 2002). A positive correlation between hippocampal theta amplitude and successful memory has been reported in human intracranial recordings (Mormann et al., 2005; Fell et al., 2003; Sederberg, Kahana, Howard, Donner, \& Madsen, 2003). Likewise, theta activity at frontal, temporal, and posterior scalp is typically modulated by successful encoding and retrieval; its amplitude is larger for remembered items compared to new or forgotten items (Osipova et al., 2006; Düzel, Neufang, \& Heinze, 2005; Burgess \& Gruzelier, 1997, 2000; Doppelmayr, Klimesch, Schwaiger, Stadler, \& Röhm, 2000; Weiss \& Rappelsberger, 2000; Doppelmayr, Klimesch, Schwaiger, Auinger, \& Winkler, 1998; Klimesch, Doppelmayr, Schimke, \& Ripper, 1997). The similar modulation of scalp-recorded theta and hippocampal theta by memory processes has led some researchers to suggest that the theta rhythm might mediate a dynamic link between hippocampus and neocortical areas that store and process long-term memory traces, as first proposed by Miller (1991).

The alpha rhythm is also modulated by memory among other cognitive activities. Alpha is the dominant rhythm during rest, and desynchronizes during mental processing. This desynchronization is manifest as a decrease in scalp-measured alpha amplitude, primarily over occipital regions. A prevalent view holds that alpha amplitude reflects cortical deactivation or inhibition and, accordingly, that alpha desynchronization reflects enhanced cortical activation (Klimesch, Sauseng, \& Hanslmayr, 2007; Pfurtscheller, 2003; Ray \& Cole, 1985; but cf. Palva \& Palva, 2007). The amount of alpha desynchronization has been correlated with intelligence as well as with individual memory ability (Doppelmayr, Klimesch, Hödlmoser, Sauseng, \& Gruber, 2005; Doppelmayr et al., 2000; Vogt, Klimesch, \& Doppelmayr, 1998; Klimesch, Doppelmayr, Pachinger, \& Ripper, 1997). During memory tasks, alpha desynchronization is influenced by semantic processing (Klimesch, Doppelmayr, \& Hanslmayr, 2006; Klimesch, Doppelmayr, Pachinger, \& Russegger, 1997; Klimesch, Schimke, \& Schwaiger, 1994) and episodic memory alike (Burgess \& Gruzelier, 2000; Weiss \& Rappelsberger, 2000; Klimesch, Doppelmayr, Pachinger, \& Ripper, 1997), although, to date, there has been no direct comparison of these effects.

Gamma band activity also seems to bear some relation to memory processes. Gamma band activity in primary and associative sensory cortices, for example, has been linked to the activation and maintenance of neural representations corresponding to an incoming stimulus (Gruber, Maess, Trujillo-Barreto, \& Müller, 2008; Jensen et al., 2007; Fries, Schröder, Roelfsema, Singer, \& Engel, 2002; Engel et al., 2001; Singer \& Gray, 1995). In working memory tasks, for example, gamma activity in visual areas is sustained throughout the retention of a stimulus' perceptual properties (Jokisch \& Jensen, 2007; Mainy et al., 2007; Howard et al., 2003). These studies and others have demonstrated that gamma activity not only reflects the processing of physical stimulus attributes but is also modulated by cognitive factors such as attention, target-matching, and working memory load (Jeschke, Lenz, Budinger, Herrmann, \& Ohl, 2008; Lenz et al., 2008; Tallon-Baudry, Bertrand, Hénaff, Isnard, \& Fischer, 2005). Furthermore, gamma activity in extrastriate regions during memory encoding predicts the likelihood of subsequent retrieval (Mainy et al., 2007; Osipova et al., 2006; Sederberg et al., 2003, 2006). It is less clear whether gamma is also increased during successful retrieval, as the reports are contradictory (Osipova et al., 2006, but cf. Düzel et al., 2005 and see Discussion). In addition, like alpha, gamma activity is also influenced by semantic variables (Gruber, Maess, et al., 2008; Lachaux et al., 2005, 2007), as reflected in greater gamma for meaningful compared to meaningless stimuli. ${ }^{1}$

The emerging picture from the literature then is that all three of these EEG frequency bands are modulated by episodic memory. However, there are still important questions to be addressed. For example, the extent to which the various reported memory effects on these rhythms reflect the actual creation and/or activation of new episodic memory traces versus other cognitive processes that contribute to or are affected by episodic memory remains unclear. Further, to a large extent, studies of neural dynamics have overlooked the critical relationship between episodic memory and pre-experimentally existing semantic knowledge. Certainly, theories of memory have hypothesized that the creation of new episodic memories benefits from preexisting knowledge in semantic memory (Tulving, 1983, 1995). Such theories have been influenced by Craik and Lockhart's (1972) Levels-of-Processing framework (see also Craik, 2002) by which episodic recognition depends on the extent of elaboration at study, that is, the richness of the preexistent associative network activated during encoding into episodic memory. Thus, it is likely that the extent of prior familiarity and/or the amount of semantic information associated with a stimulus affects the quality of episodic memory, and its neural correlates during encoding and retrieval.

According to a prevalent view, semantic memory consists of multiple subsystems encoding different types of information, for instance, verbal and perceptual (e.g., Coltheart et al., 1998; Gainotti, Silveri, Daniele, \& Giustolisi, 1995; Allport, 1985). Likewise, it has been suggested that these different types of information might be stored in various brain areas (e.g., Kellenbach, Brett, \& Patterson, 2001). In the case of faces, it is difficult to distinguish the effects of perceptual-semantics and verbal-semantics as the two are inherently confounded: Faces for which verbal-semantic information is available will also have extensive perceptualsemantic representations. Throughout this report, the term "semantic" knowledge will refer to all information—verbal and perceptual—stored in long-term memory in association with a particular face.

Surprisingly, the impact of prior semantic knowledge on episodic memory has not been directly addressed in previous investigations of the neural correlates of memory. In 
fact, a great majority of the studies cited above used familiar stimuli (e.g., words, pictures), which undoubtedly activated semantic memory traces, thus confounding episodic and semantic factors (for similar criticism, see Yovel \& Paller, 2004). This criticism is especially relevant for our understanding of the roles of alpha and gamma activity in episodic memory, as both have also been explicitly associated with perceptual and semantic processing.

To shed light on these issues, in the present study we directly tested the influence of pre-experimental familiarity with a face on the neural correlates associated with episodic memory formation and retrieval. In a classic memory recognition task, we systematically manipulated the level of semantic and episodic information available to participants. To this end, we employed both famous faces, for which participants had rich preexisting memory representations, as well as nonfamous, unfamiliar faces, for which the participants had no prior memory representations. Our rationale was that for nonfamous faces, participants' memory performance would rely wholly on the perceptual and episodic representations formed during study, whereas for famous faces episodic memory would likely be facilitated by pre-experimental semantic knowledge associated with those faces. Accordingly, and in line with the Levels-of-Processing theory, we expected episodic memory performance to be better for famous faces than for unfamiliar faces.

The primary goal of this study was to see whether and, if so, how neural activity in the theta, alpha, and gamma frequency bands, reported to be associated with episodic memory, is modulated by prior semantic knowledge during episodic memory encoding and retrieval. Our specific aims thus were twofold: First, by determining which of the frequency bands were influenced by preexisting semantic knowledge during study, we hoped to determine the neural basis for depth of processing influence on episodic memory encoding. Second, by comparing old and new faces during test, we could replicate previously reported episodic memory effects and extend the findings to include the role of semantic factors on retrieval. It is important to note that although we had a specific hypothesis regarding the famous faces advantage over nonfamous faces, we had no specific hypotheses regarding how pre-experimental familiarity with the faces might affect the neural correlates of episodic memory retrieval. At the same time, we did expect to find overall similar neural responses during study and test, as both processes are thought to involve similar neural mechanisms (Mesulam, 1998; Fuster, 1995).

\section{METHODS}

\section{Participants}

The participants were 20 undergraduates (14 women) from the Hebrew University ranging in age from 22 to 29 years (median age $=25.5$ ). All participants reported normal or corrected-to-normal vision and had no history of psychiatric or neurological disorders. Among them, one was left-handed. They signed an informed consent approved by the institutional review board of the Hebrew University, and were paid for participation or received class credit.

\section{Stimuli}

The stimuli consisted of 100 photographs of male and female unfamiliar faces and an equal number of male and female famous faces (pre-experimental familiarity with the famous faces was determined separately for each participant; see below). All the pictures were equated for mean luminance and contrast, and consisted of an equal number of male and female faces. The stimuli were presented at fixation and, seen from a distance of approximately $60 \mathrm{~cm}$, occupied $9.5^{\circ} \times 13^{\circ}$ in the visual field $(10 \mathrm{~cm} \times 14 \mathrm{~cm})$.

\section{Task and Procedure}

The experiment consisted of 10 consecutive blocks, each containing a study session followed by a test session. In the study session of each block participants viewed 20 different photographs (which were not repeated across blocks) and were instructed to judge the beauty of each face via a button press ( $1=$ pretty; 2 = average; $3=$ ugly). They were also instructed to remember the faces for subsequent testing. In the test sessions, the studied faces appeared interspersed among 20 new ones. Participants were instructed to decide whether each face was "old" or "new." They were also instructed to rate their confidence $(1=$ absolutely sure; $2=$ pretty sure; $3=$ not so sure; $4=$ not sure at all). Both at study and at test, stimuli were presented for $1500 \mathrm{msec}$, after which participants were cued to give their response. There was an ISI of 500 msec between the response and the presentation of the next stimulus. Famous and unfamiliar faces were presented in alternating blocks, with the starting block counterbalanced across participants. To ensure that participants were, in fact, familiar with the famous faces presented in the experiment, they performed a familiarity validation test at the end of the experiment. In this part, they were presented with all the famous faces and instructed to write the name and profession of the person pictured. Only faces that the participant could name or state other specific personal information about were included in the analysis (on average, subjects were familiar with $94 \%$ of the famous faces). The experiment was run in an acoustically treated and electrically isolated booth.

\section{EEG Recording}

The EEG analog signals were recorded continuously by $64 \mathrm{Ag}-\mathrm{AgCl}$ pin-type active electrodes mounted on an 
elastic cap (Electro-Cap International, Inc., Eaton, $\mathrm{OH}$ ) according to the extended 10-20 system. Eye movements, as well as blinks, were monitored using bipolar horizontal and vertical EOG derivations via two pairs of electrodes, one pair attached to the external canthi, and the other to the infraorbital and supraorbital regions of the right eye. Both EEG an EOG were sampled at $1024 \mathrm{~Hz}$ using a BioSemi Active II system (www.biosemi.com). A lowpass filter of $256 \mathrm{~Hz}$ was applied at recording to avoid aliasing. An additional electrode was placed on the tip of the nose to be used as a reference.

\section{Data Preprocessing}

Data were analyzed using the Brain Vision Analyzer (Brain Products GmBH, Gilching, Munich; www.brainproducts.com) as well as in-house Matlab routines (Mathworks, Natick, MA). Raw EEG data were high-pass filtered at $1.0 \mathrm{~Hz}$ $(24 \mathrm{~dB})$ and referenced to the tip of the nose. Eye movements and gross muscular activity were corrected using independent component analysis. Remaining artifacts exceeding $\pm 100 \mu \mathrm{V}$ in amplitude were rejected. Only correctly categorized faces were analyzed. That is, at study these included only faces that were subsequently remembered and at test these included only faces that were correctly categorized as old or new. Participants' performance was exceptionally good, with few misses or false alarms (less than 3\% on average); therefore, there were an insufficient number of trials to allow analysis of mistakes. The raw EEG signal was then segmented according to these conditions into epochs ranging from $400 \mathrm{msec}$ before to 1000 msec after stimulus onset.

\section{Local Synchronization}

We performed a wavelet analysis on the single trials at each recording site in order to obtain the amplitude and phase of the EEG activity at all frequencies ranging from 1 to $100 \mathrm{~Hz}$. To account for the different time-frequency tradeoffs for low and high frequencies, we used slightly different parameters for these two frequency bands. In all cases, we used a complex Gaussian Morlet wavelet, $w(t$, $f)=A \exp \left(-t^{2} / 2 \sigma_{t}^{2}\right) \exp (2 i \pi f t)$, where $A$ was the normalization factor $A=\left(\sigma_{t} \pi\right)^{-1 / 2}$. For frequencies between 1 and $20 \mathrm{~Hz}$, the width of the wavelet was determined according to the Morlet parameter $2 \pi \sigma_{t} f=5$ and the procedure was applied in steps of $1 \mathrm{~Hz}$, whereas for frequencies between 20 and $100 \mathrm{~Hz}$, a Morlet parameter of $2 \pi \sigma_{t} f=$ 8 was applied in 2-Hz steps. The motivation for choosing a lower Morlet parameter for the low-frequency range was to improve the temporal resolution of these frequencies which tend to be "smeared" over time. The wavelet analysis yields a complex result $\psi(t, f)=x(t, f)+i y(t, f)$ from which the amplitude $\operatorname{Amp}(t, f)=x(t, f)^{2}+y(t, f)^{2}$ and phase $\phi(t, f)=\tan ^{-1} \frac{y(t, f)}{x(t, f)}$ at each time-frequency point are extracted. Data were down-sampled in time by a factor of 4 to reduce the set size after the wavelet analysis was performed. We averaged the amplitudes at each timefrequency point across trials in each condition, and normalized them by subtracting the mean activity at each frequency level during an epoch between -300 and -100 msec from stimulus onset and dividing by the standard deviation during that time.

To reduce the possible contamination of the data by muscular artifacts related to microsaccades, which might be mistaken for cortical gamma activity (Yuval-Greenberg, Tommer, Keren, Nelken, \& Deuoell, 2008), we based the time-frequency analysis of gamma on the current source density signal (CSD; second spatial derivative of the voltage). The CSD is a reference-free signal, thus restricting the possible contamination of scalp electrodes by eye movements to those electrodes near the eyes, as opposed to the commonly used nose reference which introduces this artifact at all scalp sites (for a similar approach, see Burgess \& Gruzelier, 2000; Pulvermüller, Birbaumer, Lutzenberger, \& Mohr, 1997; Lutzenberger, Pulvermüller, Elbert, \& Birbaumer, 1995). CSD was calculated on the raw EEG segments using a spherical Laplacian (with four-spline interpolations; see Perrin, Pernier, Bertrand, \& Echallier, 1989). The raw CSD segments were then subjected to wavelet analysis, as described above. The gamma activity obtained using this method was similar in its properties to that recorded intracranial being sustained over time and limited to frequencies over $\sim 40 \mathrm{~Hz}$, thus lending credibility to our findings. In addition, we recorded EMG from the sternocleidomastoid (SCM) and trapezius muscles of a subset of participants to rule out the possibility that the gamma effects are contaminated by muscular activity (as postulated by Whitham et al., 2008). The correlation and cross-correlation between the spectral content of the event-related EMG and EEG signals were not significant $(p<.05)$, and the EMG was not modulated by the present experimental manipulations. We thus feel confident that the "gamma activity" reported here reflects, indeed, cortical activity in the gamma band.

It is customary to distinguish an increase of oscillatory activity that is phase-locked to the stimulus from that which is non-phase-locked activity (often termed "induced"). To differentiate these two types of neural dynamics, researchers often calculate the intertrial coherence (ITC), which is a measure of phase consistency across trials. A concurrent increase in amplitude and ITC reflects a phase-locked response, whereas an increase in amplitude that is not accompanied by a parallel increase in ITC reflects induced activity (Shah et al., 2004; Makeig et al., 2002). We calculated the ITC based on the phase information at each time-frequency point using a measure of spherical variance across trials $\operatorname{ITC}(t, f)=\frac{1}{N} \sum_{j=1}^{N} e^{i \phi^{j}}$. These values were $Z$-Fisher transformed to maintain a normal distribution and baseline-corrected relative to an epoch between -300 and $-100 \mathrm{msec}$ before stimulus onset. 
Statistical analysis was performed separately for each of the frequency bands (theta $=4-8 \mathrm{~Hz}$, alpha $=9-13 \mathrm{~Hz}$, gamma $=40-100 \mathrm{~Hz}$ ). For each frequency band, we defined windows of interest (WOI), which restricted the analysis to the time windows during which a conspicuous change in amplitude relative to baseline was observed, and to recording sites exhibiting the strongest activity during this interval. These were determined based on inspection of the average response to all stimuli, collapsed across conditions. In addition, we verified that the mean activity in each WOI significantly differed from baseline using a paired $t$ test.

Differences between conditions in each frequency band were established by two statistical analyses of the mean amplitudes in each WOI. In the study phase, we investigated the semantic effect of preexisting knowledge during the formation of new episodic traces. A paired $t$ test was used to compare the activity elicited by famous and nonfamous faces. In the test phase, we investigated both the semantic factor (famous vs. nonfamous faces) and the episodic factor (old vs. new faces) using a twoway ANOVA with repeated measures. In cases where bilateral activity was found, the factor hemisphere (left, right) was added into the ANOVA, making it a threeway ANOVA. In addition, in order to determine whether the activity in each WOI is phase-locked or not phaselocked (induced), we performed a $t$ test on the mean ITC in each WOI, collapsed across conditions. If the ITC differed significantly from zero, the activity in that WOI was described as phase-locked. Otherwise, it was considered induced.

Because we cannot assume that the time-frequency amplitudes and ITC values are normally distributed, the significance levels in all statistical tests were determined using a permutation test. For each subject, we randomly reassigned values to conditions and reran the relevant ANOVA or $t$ test. This procedure was repeated 1000 times, yielding a data-driven distribution of $t$ values or $F$ values. The significance levels reported are relative to this distribution (Jokisch \& Jensen, 2007; Nichols \& Holmes, 2002; Burgess \& Gruzelier, 2000).

\section{RESULTS}

\section{Behavioral Results}

Overall, participants were very good at remembering all of the studied faces, but did perform better with famous than nonfamous faces (Figure 1A). To reduce the likelihood of including trials in which participants guessed, we discarded trials on which participants' confidence was low (rated 3 or 4 ; approximately $9 \%$ of the trials). For the remaining trials, participants correctly recognized 95.55\% of the old famous faces and $86.45 \%$ the old nonfamous faces. Of the new faces, participants erroneously categorized $1.75 \%$ famous faces and $10.5 \%$ nonfamous faces as old. For each participant, we calculated the $d$-prime statis-

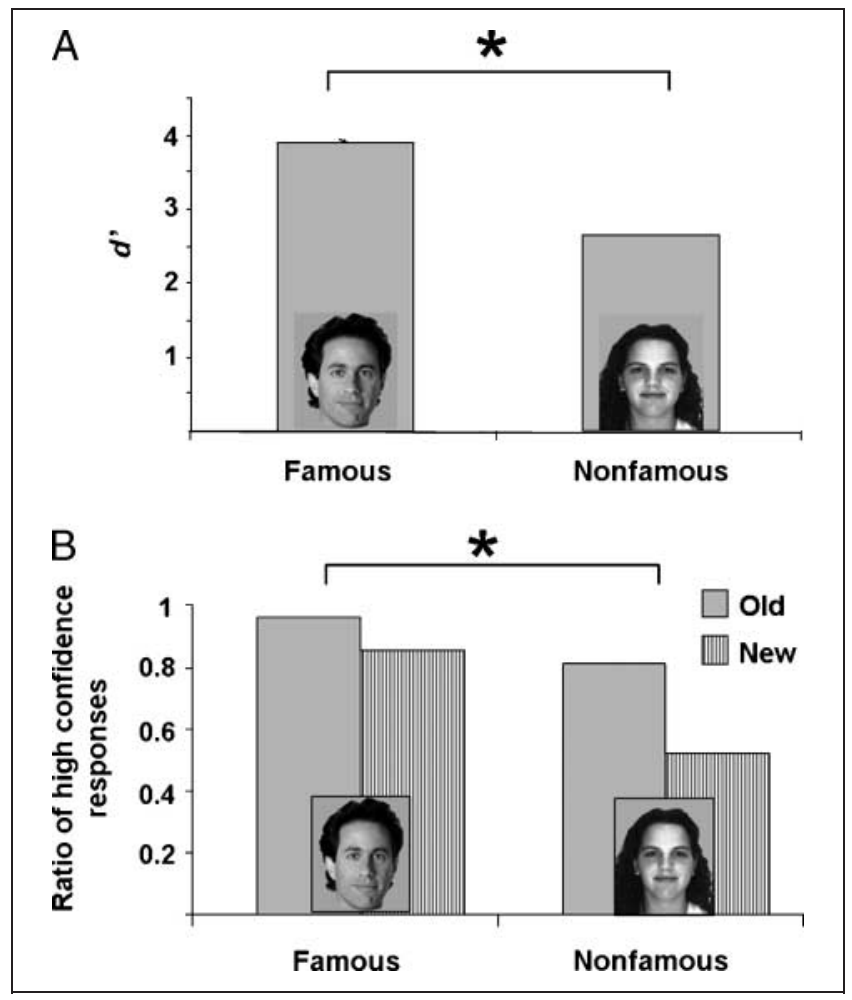

Figure 1. (A) $d^{\prime}$ scores on the old/new recognition test for famous and nonfamous faces. Overall, participants performed well on this task, and had better recognition memory for famous than nonfamous faces. (B) The proportion of high confidence responses (Confidence Level 1) was higher for both old and new famous faces, relative to nonfamous faces.

tic $\left(d^{\prime}\right)$, which is a measure of sensitivity for discriminating between any two categories (in this case, "old" and "new" items); $d^{\prime}$ is calculated by obtaining the $Z$-scores for the hit rate and false alarm rate individually for each participant, and subtracting the two. These statistics were subjected to a paired $t$ test comparing memory for famous and nonfamous faces, which yielded a significant semantic effect $[t(19)=11.0, p<.001]$.

Moreover, even with low confidence trials removed, participants were more confident in their responses for famous compared with nonfamous faces (Figure 1B). Among the correctly recognized old faces that were given high confidence rates ( 1 or 2$)$, the relative percentage of responses with confidence rating 1 was $95 \%$ for famous faces and $80 \%$ for nonfamous faces. Similarly, among the correctly categorized new faces, the relative percentage of responses with confidence rating 1 was $85 \%$ for famous faces and $52 \%$ for nonfamous faces. The difference between the percent of confidence 1 responses for famous versus nonfamous faces was statistically significant $[t(19)=7.98, p<.0001$ for old; $t(19)=5.85, p<.0001$ for new; Table 1].

In order to assist episodic memory formation, during study participants were asked to evaluate the beauty of each face. On average, more of the famous faces were 
Table 1. Behavioral Results on the Old/New Recognition Test for Famous and Nonfamous Faces

\begin{tabular}{|c|c|c|c|c|c|c|c|c|}
\hline \multirow{3}{*}{$\frac{\text { Old/New Response }}{\text { Confidence Level Response }}$} & \multicolumn{4}{|c|}{ Old } & \multicolumn{4}{|c|}{ New } \\
\hline & \multicolumn{2}{|c|}{$\begin{array}{c}\text { Correct } \\
\text { Answer (Hit) }\end{array}$} & \multicolumn{2}{|c|}{$\begin{array}{c}\text { Wrong } \\
\text { Answer (Miss) }\end{array}$} & \multicolumn{2}{|c|}{$\begin{array}{l}\text { Correct Answer } \\
\text { (Correct Rejection) }\end{array}$} & \multicolumn{2}{|c|}{$\begin{array}{l}\text { Wrong Answer } \\
\text { (False Alarm) }\end{array}$} \\
\hline & 1 & 2 & 1 & 2 & 1 & 2 & 1 & 2 \\
\hline Famous faces & $91.85 \%$ & $3.7 \%$ & $0.85 \%$ & $0.85 \%$ & $82 \%$ & $13.25 \%$ & $1.2 \%$ & $0.55 \%$ \\
\hline Nonfamous faces & $70.6 \%$ & $15.85 \%$ & $1.35 \%$ & $3.55 \%$ & $36.4 \%$ & $29.95 \%$ & $4.3 \%$ & $6.25 \%$ \\
\hline
\end{tabular}

Recognition memory was better and the participants responded with higher confidence levels for famous than nonfamous faces.

judged as pretty than nonfamous faces $[t(19)=12.4$, $p<.0001]$, and more of the nonfamous faces were considered ugly than famous faces $[t(19)=3.4, p<.05]$.

\section{Electrophysiological Results ${ }^{2}$}

\section{Early Phase-locked Response}

Examination of the time-frequency plots obtained from averaging together all the conditions revealed an early phase-locked response during the first $400 \mathrm{msec}$ after stimulus onset, spanning the entire spectrum from 1 to $40 \mathrm{~Hz}$ [see selection of WOIs in Figure 2; ITC $t(19)=$
7.9, $p<.001]$. The amplitude of this response decreased at higher frequencies and it was strongest in the theta range. This phase-locked response was maximal at centrooccipital site $\mathrm{Oz}$, and probably reflects the spectral breakdown of the P1-N1 complex of the sensory ERP (Gruber, Klimesch, Sauseng, \& Doppelmayr, 2005). Statistical analysis focused on these two electrodes and the factor hemisphere (left, right) was added into a three-way ANOVA with repeated measures. The phase-locked response was not modulated by the experimental conditions, nor were there any reliable effects or interactions [study: hemisphere, $F(1,19)=2.53, p=.12$; semantic, $F(1,19)<$ 1.0; test: hemisphere, $F(1,19)=2.08, p=.17$; semantic,
Figure 2. Demonstration of the time-frequency WOIs chosen for statistic analysis in (A) the low-frequency range $(1-20 \mathrm{~Hz})$ and $(\mathrm{B})$ the high-frequency range (20-100 Hz; based on CSD). WOIs were chosen based on the mean time-frequency plots of the amplitude (top) averaged across all experimental conditions. Hot colors indicate amplitudes higher than baseline, whereas cold colors indicate amplitudes lower than baseline (i.e., desynchronization). Each WOI was categorized as phase-locked or induced based on the mean ITC in the WOI (bottom). The phase-locked WOIs are delineated by solid rectangles, and the induced WOIs are delineated by dashed rectangles. (C) Scalp distributions of the amplitudes in each WOI are depicted to illustrate where the maximal activity was found.

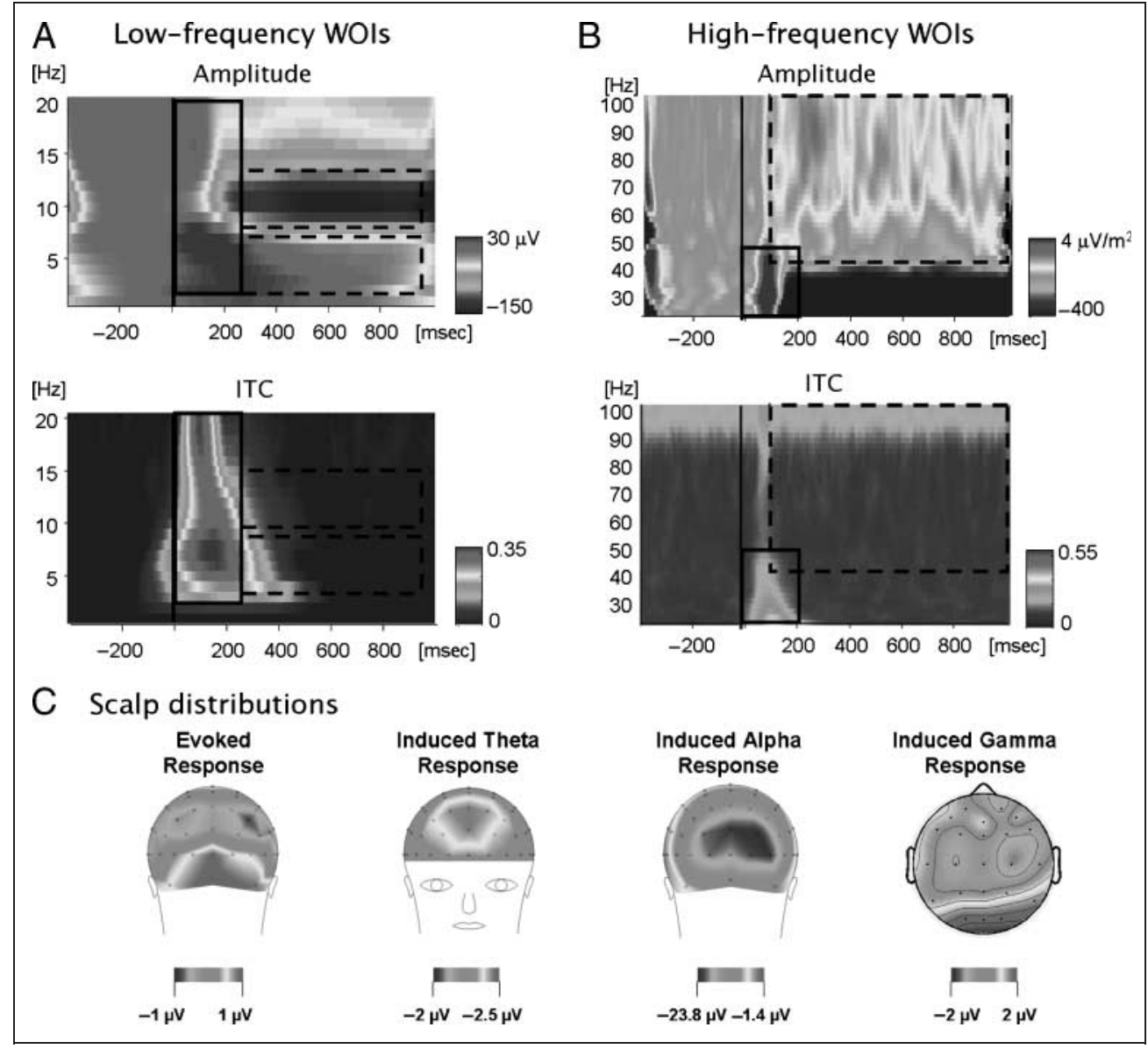


$F(1,19)=1.97, p=.17$; episodic, $F(1,19)=1.21, p=$ .28 ; Figure 3]. Due to the lack of experimental modulation, this early phase-locked response will not be further discussed.

\section{Late Induced Response}

Induced theta activity (4-8 Hz) was observed between 400 and $800 \mathrm{msec}$ [see selection of WOIs in Figure 2; ITC $t(19)<1.0$ ), primarily at frontal sites. Electrode Fz was chosen for statistical analysis. At study, frontal theta amplitudes were larger for famous than for nonfamous faces $[t(19)=1.75, p<.04]$. At test, old faces elicited higher theta than new faces $[F(1,19)=5.946, p<.02]$. There was no main effect of the semantic factor $[F(1$, $19)=1.65, p=.24]$, and no reliable interactions $(F<$ 1.0; Figure 4A).

Alpha amplitude (8-12 Hz) decreased below baseline starting around $200 \mathrm{msec}$ and lasted throughout the analyzed epoch, reflecting desynchronization. This desynchronization was of an induced nature [ITC $t(19)<$ 1.0] and was maximal at $\mathrm{Oz}$ (see selection of WOIs in Figure 2). A significant modulation of alpha desynchronization by semantic knowledge was observed during study $[t(16)=2.14, p<.02]$, with a larger amplitude decrease for famous than for nonfamous faces. During test, there was no semantic effect $(F<1)$ but the desynchronization was larger for old than for new faces $[F(1,19)=6.99$, $p<.01$; Figure 4B]. Some authors report differences between lower (8-10 Hz) and upper (10-12 Hz) alpha activity (e.g., Klimesch et al., 2006). We also performed the analysis separately for these two frequency bands, and found both these ranges were similarly modulated by our manipulations with no distinction between them.
Induced gamma activity (40-100 Hz) increased relative to baseline at occipital sites starting from $100 \mathrm{msec}$ and was sustained throughout the epoch, although the amplitude decreased over time [see selection of WOIs in Figure 2 ; ITC $t(19)<1.0$ ]. During study there was a significant semantic effect $[t(19)=-2.31, p<.05]$, with famous faces exhibiting higher amplitudes than nonfamous faces. At test, a significant episodic effect $[F(1,19)=$ $4.66, p<.05]$ revealed higher amplitudes for new items than for old items. A semantic effect showed a similar but nonsignificant trend as during study $[F(1,19)=3.24$, $p=.065]$. The semantic and episodic interaction also was not significant $(F<1.0$; Figure 5$)$.

\section{DISCUSSION}

The present study investigated neural activity in three frequency ranges during the encoding and the retrieval of episodic memories of human faces with a focus on the extent to which memory-related activities are modulated by pre-experimental semantic knowledge. As expected, recognition memory was better and participants' associated confidence levels were higher for famous than for nonfamous faces. Clearly, prior semantic knowledge about faces can assist episodic recognition under these conditions. Critically, induced activity in the theta, alpha, and gamma bands were differentially modulated by both episodic and semantic factors, enabling us to explore the neural underpinnings of the various interactions between semantic and episodic factors in face recognition memory.

Pre-experimental semantic knowledge affected neural activity in these three frequency bands primarily during

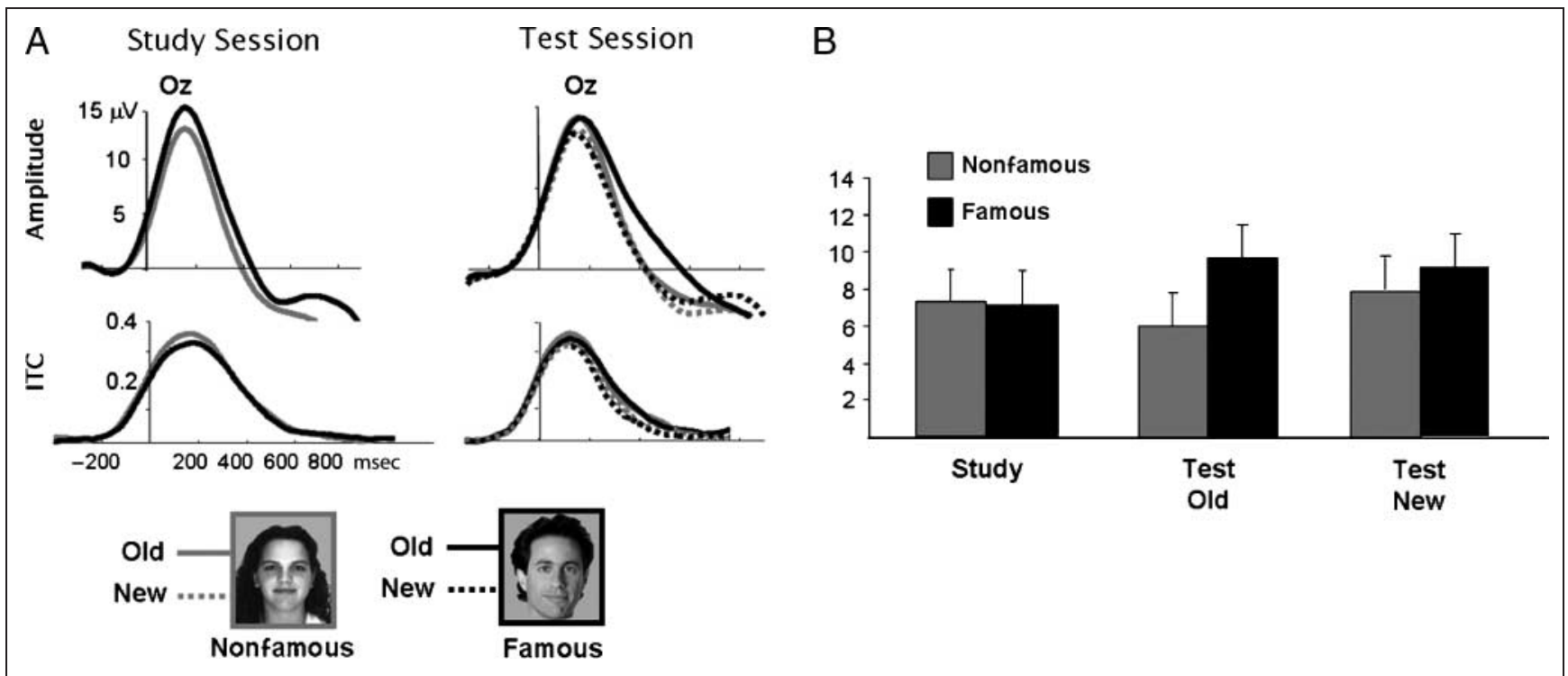

Figure 3. (A) Time course of the phase-locked response in the low-frequency range during the study and test sessions at electrode Oz. (B) Mean amplitude of the phase-locked response at electrode $\mathrm{O} 2$ between 0 and 400 msec. The phase-locked response was not significantly modulated by the present experimental manipulations. 


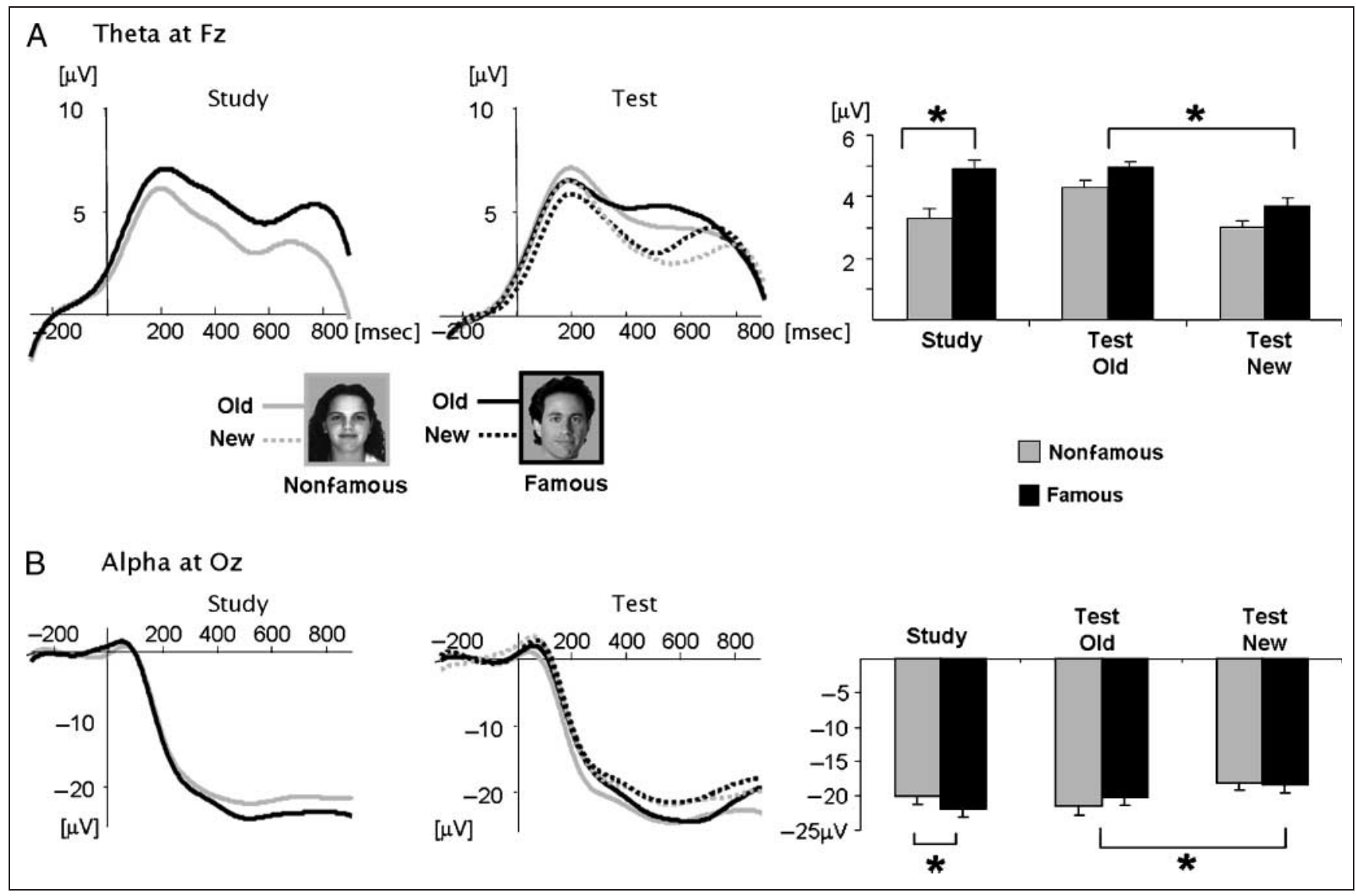

Figure 4. (A) Time course of induced theta amplitude during the study and test sessions at electrodes Fz (left) and mean theta amplitudes in the chosen WOI in all conditions (right). (B) Time course of induced alpha amplitude during the study and test sessions at electrodes Oz (left) and mean alpha amplitudes in the chosen WOI in all conditions (right). Both theta and alpha amplitudes were significantly modulated by the semantic factor during study and by the episodic factor during test.

the formation/encoding of new episodic memories (i.e., during study). The advantage for famous faces during study was manifest in increased frontal theta and occipital gamma amplitudes as well as a larger decrease in occipital alpha for famous (compared to nonfamous) faces.

Moreover, during episodic retrieval (i.e., during test), all three frequency bands were affected by the old/new status of a stimulus, albeit differently in the different frequency band. Frontal theta and occipital alpha responses ${ }^{3}$ were larger in response to old than to new faces. In contrast, the occipital gamma response decreased for old faces compared to new faces. Furthermore, although gamma activity maintained a trend of a semantic effect during the test stage, which was in a similar direction as that found at study, the semantic effect was totally eliminated at test in the theta and alpha bands. Overall, this pattern supports the association of theta, alpha, and gamma activity to episodic retrieval; however, it seems that the two former frequency bands contribute differently to episodic memory than the latter.

Because theta and alpha activity were similarly modulated, we discuss their effects jointly but follow with some ideas about their distinctions. The episodic memory effect on theta activity reported here was manifest in larger amplitudes for old compared to new faces. This pattern is congruent with previous studies of episodic memory from human intracranial and scalp recordings (see Introduction). Indeed, theta involvement in long-term potentiation as well as in memory encoding, maintenance, and retrieval are well established (Greenstein, Pavlides, \& Winson, 1988; Larson, Wong, \& Lynch, 1986). Similarly, episodic memory has been linked to increased alpha desynchronization (i.e., decrease relative to baseline) in a similar manner to that reported here (Burgess \& Gruzelier, 2000; Weiss \& Rappelsberger, 2000; Klimesch, Doppelmayr, Pachinger, \& Ripper, 1997). The agreement between the present results and the literature lends credence to our experimental setup while also establishing theta and alpha as reliable correlates of episodic memory retrieval, and allows us to hypothesize about the modulation of this activity by semantic factors.

Pre-experimental semantic knowledge increased theta and alpha responses during study (encoding) but not during the test (retrieval) stage. These findings were initially surprising, as many researchers have suggested that encoding and retrieval rely on similar neural mechanisms (e.g., Mesulam, 1998; Fuster, 1995). However, this pattern makes sense from a perspective of task-driven utilization 
of prior information. At study, pre-experimental information is beneficial for encoding a face into memory. In line with the Levels-of-Processing framework, integrating a newly formed episodic trace into an extensive network of associations activated by a familiar stimulus renders the trace stronger, thereby facilitating its subsequent retrieval (Craik \& Tulving, 1975; Craik \& Lockhart, 1972). In contrast, at test, deciding whether or not a certain stimulus has been seen during study might, in fact, be hindered by semantic familiarity. If both old and new familiar items activate extensive associative networks that are irrelevant to their episodic status, it would be more difficult to distinguish among members of the two categories. Therefore, we suggest that the memory processes reflected by theta and alpha activity are not impervious to preexisting semantic information, but utilize it selectively, namely, only when it is beneficial to the task at hand.

This line of reasoning leads to a number of testable predictions for future investigation. For example, intermingling famous and nonfamous face in the same memory retrieval block might render the semantic information relevant for retrieval per se, thereby leading to its use. Similarly, to the extent that the recognition task is made more difficult and/or the face identity becomes more task relevant, preexisting information becomes more useful, and thus, more likely to affect the memory retrieval increases manifest in theta and alpha activity.

The modulation of alpha desynchronization by semantic processing has been observed in several studies (e.g., Freunberger, Klimesch, Griesmayr, Sauseng, \& Gruber, 2008; Klimesch, Doppelmayr, Pachinger, \& Ripper, 1997; Klimesch et al., 1994). Röhm, Klimesch, Haider, and Doppelmayr (2001), for example, found that alpha desynchronization increases according to the semantic demands imposed by different tasks, which supports the view that alpha desynchronization is influenced by semantics selectively. By contrast, modulation of theta activity by semantic processing has not been reported to our knowledge, although its involvement in episodic memory and working memory is well established (Kahana, Seelig,

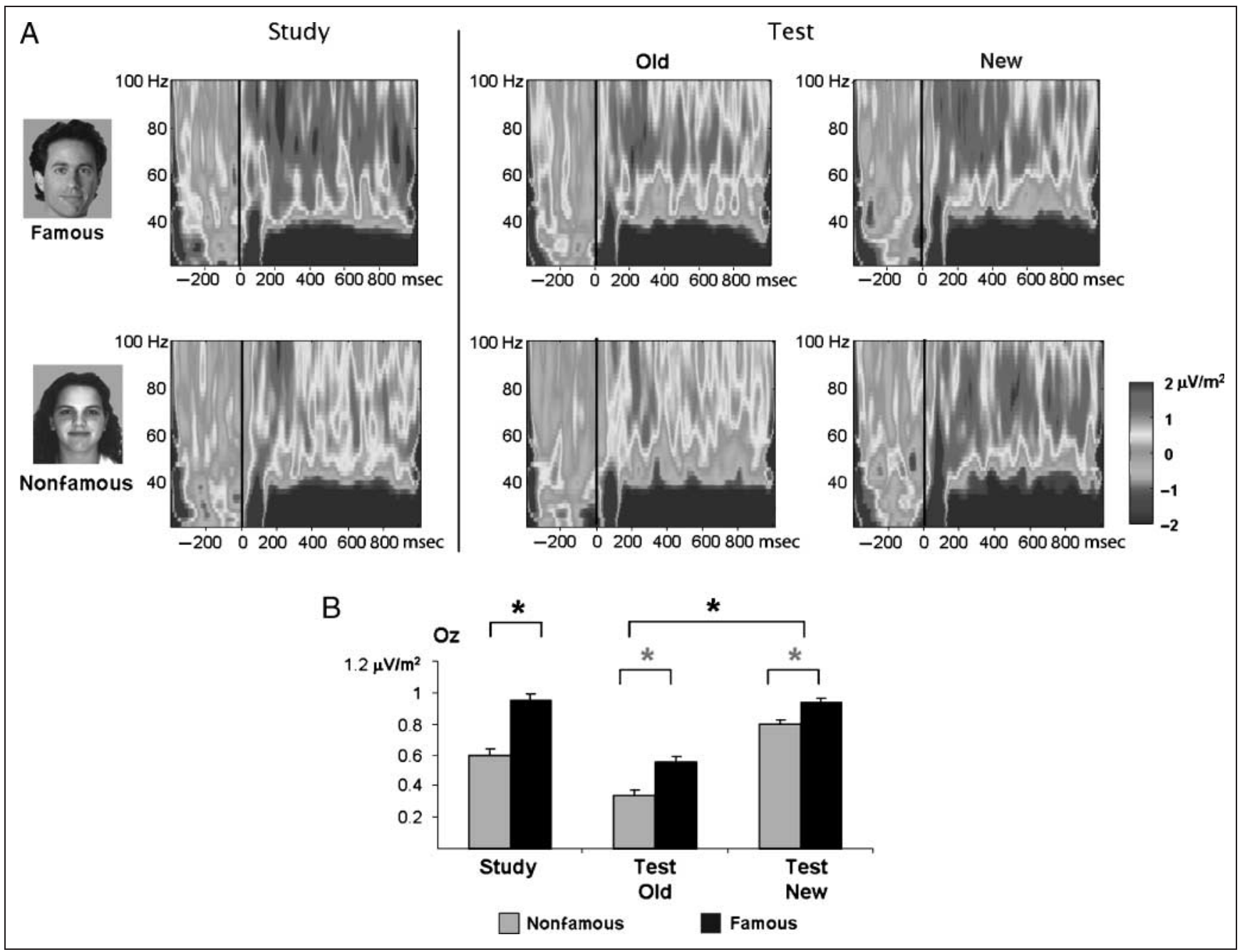

Figure 5. (A) Time-frequency plots illustrating the amplitude of the CSD signal in the high-frequency range, between 20 and $100 \mathrm{~Hz}$. (B) Mean induced gamma amplitude in the chosen WOI. During study, famous faces elicited higher gamma than nonfamous faces, and a similar trend was found during test (gray asterisks). In addition, during test, gamma amplitude decreased for old faces relative to new faces. 
\& Madsen, 2001). Klimesch et al. (2006) attributed the differential sensitivity of theta and alpha to semantics as due to their involvement in different types of memory processing. Specifically, they suggested that alpha desynchronization is related to long-term memory, whereas theta is associated with short-term/working memory. The present results demonstrate for the first time that even if, as suggested, theta is related primarily to short-term memory, this process is not impervious to influences from longterm semantic memory. Rather, semantics probably assists the memory encoding process, which is reflected by modulation in theta activity.

The induced theta and alpha responses had a similar time course, exhibiting a relatively late onset $(\sim 200 \mathrm{msec}$ after stimulus presentation) and a prolonged duration (compared, for example, with the early phase-locked theta response). This time course is more consistent with a secondary/recurrent rather than initial processing stage. Theories of memory retrieval suggest that hippocampal activation is followed by (back-) propagation from hippocampus to other cortical areas that originally supplied it with input and/or are involved in storing long-term memory representations (e.g., Moscovitch, Nadel, Winocur, Gilboa, \& Rosenbaum, 2006; Nadel \& Moscovitch, 1997; Treves \& Rolls, 1994). It is possible that our observations of semantic and episodic memory on induced frontal theta and occipital alpha reflect the interaction of hippocampal regions with frontal and occipital regions, respectively.

Several lines of evidence support this hypothesis, albeit indirectly. For one, theta rhythm has been explicitly implicated as providing a dynamic link between hippocampus and frontal, prefrontal, and temporal neocortex involved in storing long-term memory representations (Düzel et al., 2005; Kirk \& Mackay, 2003; Newman \& Grace, 1999; Miller, 1991). This association is supported primarily by the similarity in the modulations of cortical and hippocampal theta in memory tasks. Moreover, in a recent study, Siapas, Lubenov, and Wilson (2005) demonstrated that prefrontal theta in the rat brain is phase-locked to hippocampal theta. This important finding provides additional support for the notion that the theta rhythm mediates communication between these two regions. Another line of evidence comes from findings demonstrating back-propagation from the monkey hippocampus to extrastriate regions. Face-specific responses in inferior temporal cortex (IT) are elicited at about $200-350 \mathrm{msec}$, whereas perirhinal activation is observed as early as 90 msec (Henson et al., 2003; Brown \& Xiang, 1998; Treves \& Rolls, 1994; Perrett, Rolls, \& Caan, 1982). Although no direct connection has been made between this back-propagation and the alpha rhythm, there are several reasons why the memory effects on alpha might be related to hippocampal inputs. First, the onset of alpha suppression fits with the presumed timing of feedback responses from hippocampus to extrastriate regions. Second, multimodal cortical areas in superior temporal sulcus - the presumed source of the cortical alpha rhythm-receive inputs directly from hippocam- pus (Steriade, Gloor, Llinás, Lopes de Silva, \& Mesulam, 1990). In addition, Von Stein, Chiang, and König (2000) implied the susceptibility of occipital alpha to top-down influences by demonstrating that alpha activity in primary cat visual cortex is driven by input from higher-order areas. In short, although to date there is no direct evidence attributing semantic memory effects on frontal theta and occipital alpha to episodic influences from hippocampus, we believe that this is a plausible and testable hypothesis.

The third frequency band of interest in the current study was the gamma band. We found that gamma activity was influenced by semantic knowledge during study, displaying higher amplitudes for famous than for nonfamous faces. Our results support the association of gamma activity in the occipital areas with activation of preexisting neural representation corresponding to an incoming visual stimulus (Jensen et al., 2007). In concert, this pattern is in line with demonstrations of larger gamma activity for coherent and meaningful stimuli compared to meaningless stimuli (Gruber, Maess, et al., 2008; Zion-Golumbic \& Bentin, 2007; Lachaux et al., 2005; Singer \& Gray, 1995). The greater gamma activity in response to famous faces probably reflects activation of a more elaborate neural representation for these faces compared to unfamiliar ones (see also Anaki, Zion-Golumbic, \& Bentin, 2007). This elaborate semantic information may have facilitated episodic encoding by reinforcing the already existent associations. Supporting this view, previous studies showed that the degree of gamma activity in extrastriate regions during episodic encoding has been found to predict subsequent episodic memory performance (Mainy et al., 2007; Osipova et al., 2006).

The differences between famous and nonfamous faces may further suggest that gamma activity reflects activation of the most specific and individualized neural representation. For famous faces, representations corresponding to individual exemplars (e.g., "Jerry Seinfeld," "Margaret Thatcher") are accessed, whereas for unfamiliar faces, only categorical or subordinate-categorical representation can, in principle, be activated (e.g., "man," "woman"; regarding the default level of face categorization, see Tanaka, 2001). A similar interpretation of modulations in gamma amplitude as reflecting different levels of categorization was given to explain higher gamma activity for faces compared to nonface stimuli (Zion-Golumbic, Golan, Anaki, \& Bentin, 2008).

Although the semantic effect in the current study was significant during study, it showed only a trend in that direction at test. As discussed above for the theta and alpha activity, just how much and what information is "automatically" activated in association with a particular stimulus may be driven by the demand characteristics of the task. Perhaps episodic recognition relies on semantic information less than encoding does, as reflected in the reduced semantic effect at test. This is, of course, a testable hypothesis. The notion of selective and taskdependent activation of the neural representations is supported by the significantly smaller gamma amplitudes 
for old faces at test compared to both new faces and to the same faces presented during study. This pattern is similar to previous findings reporting larger gamma amplitudes for correctly classified "new" words versus correctly recognized "old" words (Düzel et al., 2005). It is also consistent with gamma repetition suppression, that is, smaller gamma amplitudes elicited by repeated items compared to those presented for the first time (Trautner et al., 2006; Gruber \& Müller, 2002, 2005) as well as with the smaller gamma amplitudes for primed versus unprimed words (semantic factors; Düzel, Habib, Guderian, \& Heinze, 2004). A similar pattern of repetition suppression has also been observed in monkey inferior temporal cortex (Li, Miller, \& Desimone, 1993) and in human BOLD signal in fMRI studies (Fiebach, Gruber, \& Supp, 2005; Henson \& Rugg, 2003; on the relationship between gamma activity and the BOLD signal, see Lachaux et al., 2007; Nir et al., 2007).

It has been suggested that gamma activity suppression when accessing a neural representation/semantic neighborhood for a second (vs. initial) time may reflect activation of a sparser network due to a "sharpening" of the representation (Axmacher, Elger, \& Fell, 2008; Pexman, Hargreaves, Edwards, Henry, \& Goodyear, 2007). Gamma repetition suppression is also a consequence of episodic factors to the extent that it reflects the fact that an item has recently been seen and, therefore, less information needs to be reactivated. However, we note an MEG study reporting patterns inconsistent with gamma repetition suppression (Osipova et al., 2006); specifically, these authors found a small but significant increase in gamma amplitude for correctly remembered old landscapes versus correctly classified new ones, although not for old versus new buildings. These discrepant patterns of gamma clearly need to be investigated.

One alternative explanation for the semantic effects reported here is that famous faces attract more attention than nonfamous faces. Indeed, famous and distinct faces tend to be processed more efficiently, a trait which may be due to allocation of attention (Ryu \& Chaudhuri, 2007; Jackson \& Raymond, 2006). In addition, the bias found here for judging famous faces as more attractive than nonfamous faces might be related to their attracting more attention (although this may also be due to a social bias in deeming celebrities as beautiful, see also Halberstadt, 2006; Peskin \& Newell, 2004). This is a viable interpretation especially because theta, alpha, and gamma synchronization are also known to be influenced by attention (Jensen et al., 2007; Sauseng, Hoppe, Klimesch, Gerloff, \& Hummel, 2007). However, on this hypothesis, we would expect attentional effects to be similar in both the study and test sessions, which was not the case in any of our measures. We thus believe that the present data do not support the hypothesis that differences between theta, alpha, and gamma synchronization for famous and nonfamous faces in this particular task stem from differential allocation of attention, but rather from differential utilization of semantic information for mnemonic tasks at hand.

Finally, we note that famous and nonfamous faces differ from each other not only in the richness of the information associated with each but also in perceptual familiarity, which is also greater for famous faces. The design of the present study does not enable us to determine to what extent the observed differences between famous and nonfamous faces during study reflect either or both of these differences. This issue can be addressed in studies that compare famous faces to perceptually similar faces that are not characterized by an elaborate verbal semantic network.

\section{Conclusion}

We find that the formation of episodic memory for faces is facilitated by preexisting semantic information as reflected in performance on the episodic recognition task. This facilitation is manifest in all three frequency bands investigated here- - theta and gamma synchronization and alpha desynchronization-all enhanced for famous face compared to nonfamous faces during study. By contrast, preexisting semantic knowledge played a marginal role at test as reflected by nonreliable semantic effects in these three frequency bands. This pattern suggests a fundamental difference in the reliance of encoding and retrieval processes on semantic information and is indicative of the distinction between these processes.

Moreover, we find that during test, activity in the theta and alpha bands is differentially modulated by episodic memory compared to gamma band activity. The pattern of these modulations, taken together with the extensive literature on the various factors affecting each frequency band, suggests they have different relationships to episodic retrieval and different roles in this process. Specifically, we hypothesize that gamma activity reflects the extent of the preexisting neural associations activated in response to a visual stimulus, whereas frontal theta synchronization and occipital alpha desynchronizations reflect episodic memory processes per se, which utilize semantic information when it is beneficial for task performance. This claim is in line with a recent study demonstrating that occipital gamma activity is modulated by stimulus familiarity, whereas theta activity is modulated by explicit episodic recollection (Gruber, Tsivilis, Giabbiconi, \& Müller, 2008).

We believe that, in concert, our broad-range analysis of several EEG frequency bands provides new insights into the complex interplay between neural mechanisms contributing to semantic and episodic memory processes for faces. Specifically, we find that although there is clearly a strong interdependence between the neural mechanisms supporting episodic and semantic memory, the various influences of these two distinct memory processes can be differentiated by investigating their effects on neural synchronization in multiple frequency bands. The present study invites aggressive investigation of the functional roles 
of neural synchronization on the different aspects of recognition memory in general, and for faces in particular.

\section{Acknowledgments}

We thank Victoria Aizenberg for meticulous and professional research assistance. This study was supported by NIMH grant R01 MH $544 S 6$ to Shlomo Bentin. Elana Zion-Golumbic was partially supported by the Noah Royal foundation.

Reprint requests should be sent to Elana Zion-Golumbic, Department of Neurology, Columbia University Medical Center, $710 \mathrm{~W}$ 168th St. NI-741, New York, NY 10032, or via e-mail: elana.golumbic@mail.huji.ac.il.

\section{Notes}

1. In discussing gamma-band modulations, we must address previous studies by us and others that show a transient, broadband burst of high-frequency activity in the EEG signal around 200$300 \mathrm{msec}$. This activity is larger in response to stimuli for which participants have a preexisting mental representation such as familiar objects (Gruber \& Müller, 2005; Tallon-Baudry, Bertrand, Delpuech, \& Permier, 1996, 1997) and larger for faces relative to other meaningful stimuli (Zion-Golumbic et al., 2008). Moreover, this type of activity is higher for famous than unfamiliar faces (Anaki et al., 2007). However, a recent study by Yuval-Greenberg et al. (2008) convincingly demonstrates that much of this activity can be accounted for by microsaccades, casting serious doubts on the validity of this measure as neural gamma-band activity. The results of all these studies thus need to be reconsidered and interpreted with caution. That said, the existence of neural gammaband activity remains a robust finding, as clearly demonstrated by intracranial and MEG studies, which are less prone to muscular artifacts from microsaccades and other eye movements (and, in some cases, have reported similar gamma-band modulations as in the EEG studies, e.g., Gruber, Maess, et al., 2008). We believe that if adequate measures are taken to deal with possible contamination of eye movements, neural gamma activity also can be recorded using scalp EEG. Consequently, in the present study, we base the analysis of gamma activity on the second spatial derivative (CSD) instead of the raw EEG (see Methods).

2. The electrophysiological results presented here focus entirely on frequency decomposition of the raw EEG signal, as this was the primary interest of the current research. However, traditional analysis of ERPs was also conducted. Results were consistent with what has previously been reported in the literature, demonstrating similar episodic and semantic effects on the late ERP components (the N400 and P600; e.g., Yovel \& Paller, 2004; Eimer, 2000). These results did not contribute much to the present research question concerning the interplay between episodic and semantic factors in memory for faces nor regarding the different neural mechanisms that might contribute to these different processes. Therefore, this analysis is not presented in the current article.

3. Throughout the article the term "induced alpha response" refers to alpha decrease/desynchronization. Thus, the larger the decrease in alpha relative to baseline, the larger the "alpha response."

\section{REFERENCES}

Allport, D. A. (1985). Distributed memory, modular subsystems and dysphasia. In S. K. Newman \& R. Epstein (Eds.), Current perspectives in dysphasia (pp. 32-60). Edinburgh: Churchill Livingstone.
Anaki, D., Zion-Golumbic, E., \& Bentin, S. (2007) Electrophysiological neural mechanisms for detection, configural analysis and recognition of faces. Neuroimage, 37, 1407-1416.

Axmacher, N., Elger, C. E., \& Fell, J. (2008). Memory formation by refinement of neural representations: The inhibition hypothesis. Behavioural Brain Research, 189, 1-8.

Brown, M. W., \& Xiang, J. Z. (1998). Recognition memory: Neuronal substrates of the judgement of prior occurrence. Progress in Neurobiology, 55, 149-189.

Burgess, A. P., \& Gruzelier, J. H. (1997). Short duration synchronization of human theta rhythm during recognition memory. NeuroReport, 8, 1039-1042.

Burgess, A. P., \& Gruzelier, J. H. (2000). Short duration power changes in the EEG during recognition memory for words and faces. Psychophysiology, 37, 596-606.

Buzsáki, G. (2002). Theta oscillations in the hippocampus. Neuron, 33, 325-340.

Buzsáki, G. (2005). Theta rhythm of navigation: Link between path integration and landmark navigation, episodic and semantic memory. Hippocampus, 15, $827-840$

Buzsáki, G., \& Draguhn, A. (2004). Neuronal oscillations in cortical networks. Science, 304, 1926-1929.

Coltheart, M., Inglis, L., Cupples, L., Michie, P., Bates, A., \& Budd, B. (1998). A semantic subsystem of visual attributes. Neurocase, 4, 353-370

Craik, F. I. (2002). Levels of processing: Past, present, and future? Memory, 10, 305-318.

Craik, F. I., \& Lockhart, R. S. (1972). Levels of processing: A framework for memory research. Journal of Verbal Learning and Verbal Behavior, 11, 671-684.

Craik, F. I., \& Tulving, E. (1975). Depth of processing and the retention of words in episodic memory. Journal of Experimental Psychology: General, 104, 268-294.

Doppelmayr, M., Klimesch, W., Hödlmoser, K., Sauseng, P., \& Gruber, W. (2005). Intelligence related upper alpha desynchronization in a semantic memory task. Brain Research Bulletin, 66, 171-177.

Doppelmayr, M., Klimesch, W., Schwaiger, J., Auinger, P., \& Winkler, T. (1998). Theta synchronization in the human EEG and episodic retrieval. Neuroscience Letters, 257, 41-44.

Doppelmayr, M., Klimesch, W., Schwaiger, J., Stadler, W., \& Röhm, D. (2000). The time locked theta response reflects interindividual differences in human memory performance. Neuroscience Letters, 278, 141-144.

Düzel, E., Habib, R., Guderian, S., \& Heinze, H. J. (2004). Four types of novelty-familiarity responses in associative recognition memory of humans. European Journal of Neuroscience, 19, 1408-1416.

Düzel, E., Neufang, M., \& Heinze, H. J. (2005). The oscillatory dynamics of recognition memory and its relationship to event-related responses. Cerebral Cortex, 15, 1992-2000.

Eimer, M. (2000). Event-related brain potentials distinguish processing stages involved in face perception and recognition. Clinical Neurophysiology, 111, 694-705.

Engel, A. K., Fries, P., \& Singer, W. (2001). Dynamic predictions: Oscillations and synchrony in top-down processing. Nature Reviews Neuroscience, 2, 704-716.

Fell, J., Klaver, P., Elfadil, H., Schaller, C., Elger, C. E., \& Fernández, G. (2003). Rhinal-hippocampal theta coherence during declarative memory formation: Interaction with gamma synchronization? European Journal of Neuroscience, 17, 1082-1088.

Fiebach, C. J., Gruber, T., \& Supp, G. G. (2005). Neuronal mechanisms of repetition priming in occipitotemporal 
cortex: Spatiotemporal evidence from functional magnetic resonance imaging and electroencephalography. Journal of Neuroscience, 25, 3414-3422.

Freunberger, R., Klimesch, W., Griesmayr, B., Sauseng, P., \& Gruber, W. (2008). Alpha phase coupling reflects object recognition. Neuroimage, 42, 928-935.

Fries, P. (2005). A mechanism for cognitive dynamics: Neuronal communication through neuronal coherence. Trends in Cognitive Sciences, 9, 474-480.

Fries, P., Nikolić, D., \& Singer, W. (2007). The gamma cycle. Trends in Cognitive Sciences, 30, 309-316.

Fries, P., Schröder, J. H., Roelfsema, P. R., Singer, W., \& Engel, A. K. (2002). Oscillatory neuronal synchronization in primary visual cortex as a correlate of stimulus selection. Journal of Neuroscience, 22, 3739-3754.

Fuster, J. M. (1995). Memory in the cerebral cortex: An empirical approach to neural networks in the buman and nonbuman. Cambridge, MA: MIT Press.

Gainotti, G., Silveri, M. C., Daniele, A., \& Giustolisi, L. (1995). Neuroanatomical correlates of category-specific semantic disorders: A critical survey. Memory, 3, 247-264.

Gobbini, M. I., \& Haxby, J. V. (2006). Neural systems for recognition of familiar faces. Neuropsychologia, 45, 32-41.

Greenstein, Y. J., Pavlides, C., \& Winson, J. (1988). Long-term potentiation in the dentate gyrus is preferentially induced at theta rhythm periodicity. Brain Research, 438, 331-334.

Grill-Spector, K., Kushnir, T., Edelman, S., Avidan, G., Itzchak, Y., \& Malach, R. (1999). Differential processing of objects under various viewing conditions in the human lateral occipital complex. Neuron, 24, 187-203.

Gruber, T., Maess, B., Trujillo-Barreto, N. J., \& Müller, M. M. (2008). Sources of synchronized induced gamma-band responses during a simple object recognition task: A replication study in human MEG. Brain Research, 1196, 74-84.

Gruber, T., \& Müller, M. M. (2002). Effects of picture repetition on induced gamma band responses, evoked potentials, and phase synchrony in the human EEG. Cognitive Brain Research, 13, 377-392.

Gruber, T., \& Müller, M. M. (2005). Oscillatory brain activity dissociates between associative stimulus content in a repetition priming task in the human EEG. Cerebral Cortex, 15, 109-116.

Gruber, T., Tsivilis, D., Giabbiconi, C. M., \& Müller, M. M. (2008). Induced electroencephalogram oscillations during source memory: Familiarity is reflected in the gamma band, recollection in the theta band. Journal of Cognitive Neuroscience, 20, 1043-1053.

Gruber, W. R., Klimesch, W., Sauseng, P., \& Doppelmayr, M. (2005). Alpha phase synchronization predicts P1 and N1 latency and amplitude size. Cerebral Cortex, 15, 371-377.

Halberstadt, J. (2006). The generality and ultimate origins of the attractiveness of prototypes. Personality and Social Psychology Review, 10, 166-183.

Haxby, J. V., Hoffman, E. A., \& Gobbini, M. I. (2000). The distributed human neural system for face perception. Trends in Cognitive Sciences, 4, 223-233.

Henson, R. N., Goshen-Gottstein, Y., Ganel, T., Otten, L. J., Quayle, A., \& Rugg, M. D. (2003). Electrophysiological and haemodynamic correlates of face perception, recognition and priming. Cerebral Cortex, 13, 793-805.

Henson, R. N., \& Rugg, M. D. (2003). Neural response suppression, haemodynamic repetition effects, and behavioural priming. Neuropsychologia, 41, 263-270.

Howard, M. W., Rizzuto, D. S., Caplan, J. B., Madsen, J. R., Lisman, J., Aschenbrenner-Scheibe, R., et al. (2003). Gamma oscillations correlate with working memory load in humans. Cerebral Cortex, 13, 1369-1374.
Jackson, M. C., \& Raymond, J. E. (2006). The role of attention and familiarity in face identification. Perception E Psychophysics, 68, 543-557.

Jacobs, J., Kahana, M. J., Ekstrom, A. D., \& Fried, I. (2007). Brain oscillations control timing of single-neuron activity in humans. Journal of Neuroscience, 27, 3839-3844.

Jensen, O., Kaiser, J., \& Lachaux, J. P. (2007). Human gamma-frequency oscillations associated with attention and memory. Trends in Neurosciences, 30, 317-324.

Jeschke, M., Lenz, D., Budinger, E., Herrmann, C. S., \& Ohl, F. W. (2008). Gamma oscillations in gerbil auditory cortex during a target-discrimination task reflect matches with short-term memory. Brain Research, 1220, 70-80.

Jokisch, D., \& Jensen, O. (2007). Modulation of gamma and alpha activity during a working memory task engaging the dorsal or ventral stream. Journal of Neuroscience, 27, 3244-3251.

Kahana, M. J., Seelig, D., \& Madsen, J. R. (2001). Theta returns. Current Opinion in Neurobiology, 11, 739-744.

Kellenbach, M. L., Brett, M., \& Patterson, K. (2001). Large, colorful, or noisy? Attribute- and modality-specific activations during retrieval of perceptual attribute knowledge. Cognitive, Affective \& Behavioral Neuroscience, 3, 207-221.

Kirk, I. J., \& Mackay, J. C. (2003). The role of theta-range oscillations in synchronising and integrating activity in distributed mnemonic networks. Cortex, 39, 993-1008.

Klimesch, W., Doppelmayr, M., \& Hanslmayr, S. (2006). Upper alpha ERD and absolute power: Their meaning for memory performance. Progress in Brain Research, 159, 151-165.

Klimesch, W., Doppelmayr, M., Pachinger, T., \& Ripper, B. (1997). Brain oscillations and human memory: EEG correlates in the upper alpha and theta band.

Neuroscience Letters, 238, 9-12.

Klimesch, W., Doppelmayr, M., Pachinger, T., \& Russegger, H. (1997). Event-related desynchronization in the alpha band and the processing of semantic information. Cognitive Brain Research, 6, 83-94.

Klimesch, W., Doppelmayr, M., Schimke, H., \& Ripper, B. (1997). Theta synchronization and alpha desynchronization in a memory task. Psychophysiology, 34, 169-176.

Klimesch, W., Sauseng, P., \& Hanslmayr, S. (2007). EEG alpha oscillations: The inhibition-timing hypothesis. Brain Research Reviews, 53, 63-88.

Klimesch, W., Schimke, H., \& Schwaiger, J. (1994). Episodic and semantic memory: An analysis in the EEG theta and alpha band. Electroencephalography and Clinical Neurophysiology, 91, 428-441.

Lachaux, J. P., Fonlupt, P., Kahane, P., Minotti, L., Hoffmann, D., Bertrand, O., et al. (2007). Relationship between task-related gamma oscillations and BOLD signal: New insights from combined fMRI and intracranial EEG. Human Brain Mapping, 28, 1368-1375.

Lachaux, J. P., George, N., Tallon-Baudry, C., Martinerie, J., Hugueville, L., Minotti, L., et al. (2005). The many faces of the gamma band response to complex visual stimuli. Neuroimage, 25, 491-501.

Larson, J., Wong, D., \& Lynch, G. (1986). Patterned stimulation at the theta frequency is optimal for the induction of hippocampal long-term potentiation. Brain Research, 368, 347-350.

Lenz, D., Jeschke, M., Schadow, J., Naue, N., Ohl, F. W., \& Herrmann, C. S. (2008). Human EEG very high frequency oscillations reflect the number of matches with a template in auditory short-term memory. Brain Research, 1220, 81-92.

Leube, D. T., Erb, M., Grodd, W., Bartels, M., \& Kircher, T. T. (2003). Successful episodic memory retrieval of 
newly learned faces activates a left fronto-parietal network. Cognitive Brain Research, 18, 97-101.

Leveroni, C. L., Seidenberg, M., Mayer, A. R., Mead, L. A., Binder, J. R., \& Rao, S. M. (2000). Neural systems underlying the recognition of familiar and newly learned faces. Journal of Neuroscience, 20, 878-886.

Li, L., Miller, E. K., \& Desimone, R. (1993). The representation of stimulus familiarity in anterior inferior temporal cortex. Journal of Neurophysiology, 69, 1918-1929.

Lutzenberger, W., Pulvermüller, F., Elbert, T., \& Birbaumer, N. (1995). Visual stimulation alters local 40-Hz responses in humans: An EEG-study. Neuroscience Letters, 183, 39-42.

Mainy, N., Kahane, P., Minotti, L., Hoffmann, D., Bertrand, O., \& Lachaux, J. P. (2007). Neural correlates of consolidation in working memory. Human Brain Mapping, 28, 183-193.

Makeig, S., Westerfield, M., Jung, T. P., Enghoff, S., Townsend, J., Courchesne, E., et al. (2002). Dynamic brain sources of visual evoked responses. Science, 295, 690-694.

Mesulam, M. M. (1998). From sensation to cognition. Brain, 121, 1013-1052.

Miller, R. (1991). Cortico-hippocampal interplay and the representation of contexts in the brain. Berlin: Springer-Verlag.

Mormann, F., Fell, J., Axmacher, N., Weber, B., Lehnertz, K., Elger, C. E., et al. (2005). Phase/amplitude reset and theta-gamma interaction in the human medial temporal lobe during a continuous word recognition memory task. Hippocampus, 15, 890-900.

Moscovitch, M., Nadel, L., Winocur, G., Gilboa, A., \& Rosenbaum, R. S. (2006). The cognitive neuroscience of remote episodic, semantic and spatial memory. Current Opinion in Neurobiology, 16, 179-190.

Nadel, L., \& Moscovitch, M. (1997). Memory consolidation, retrograde amnesia and the hippocampal complex. Current Opinion in Neurobiology, 7, 217-227.

Newman, J., \& Grace, A. A. (1999). Binding across time: The selective gating of frontal and hippocampal systems modulating working memory and attentional states. Consciousness and Cognition, 8, 196-212.

Nichols, T. E., \& Holmes, A. P. (2002). Nonparametric permutation tests for functional neuroimaging: A primer with examples. Human Brain Mapping, 15, 1-25.

Nir, Y., Fisch, L., Mukamel, R., Gelbard-Sagiv, H., Arieli, A., Fried, I., et al. (2007). Coupling between neuronal firing rate, gamma LFP, and BOLD fMRI is related to interneuronal correlations. Current Biology, 17, 1275-1285.

Osipova, D., Takashima, A., Oostenveld, R., Fernández, G., Maris, E., \& Jensen, O. (2006). Theta and gamma oscillations predict encoding and retrieval of declarative memory. Journal of Neuroscience, 26, 7523-7531.

Palva, S., \& Palva, J. M. (2007). New vistas for alpha-frequency band oscillations. Trends in Neurosciences, 304, 150-158.

Perrett, D. I., Rolls, E. T., \& Caan, W. (1982). Visual neurones responsive to faces in the monkey temporal cortex. Experimental Brain Research, 47, 329-342.

Perrin, F., Pernier, J., Bertrand, O., \& Echallier, J. F. (1989). Spherical splines for scalp potential and current density mapping. Electroencephalography and Clinical Neurophysiology, 72, 184-187.

Peskin, M., \& Newell, F. N. (2004). Familiarity breeds attraction: Effects of exposure on the attractiveness of typical and distinctive faces. Perception, 33, 147-157.

Pexman, P. M., Hargreaves, I. S., Edwards, J. D., Henry, L. C., \& Goodyear, B. G. (2007). The neural consequences of semantic richness: When more comes to mind, less activation is observed. Psychological Science, 18, 401-406.

Pfurtscheller, G. (2003). Induced oscillations in the alpha band: Functional meaning. Epilepsia, 44(Suppl. 12), 2-8.
Pulvermüller, F., Birbaumer, N., Lutzenberger, W., \& Mohr, B. (1997). High-frequency brain activity: Its possible role in attention, perception and language processing. Progress in Neurobiology, 52, 427-445.

Ray, W. J., \& Cole, H. W. (1985). EEG alpha activity reflects attentional demands, and beta activity reflects emotional and cognitive processes. Science, 228, 750-752.

Röhm, D., Klimesch, W., Haider, H., \& Doppelmayr, M. (2001). The role of theta and alpha oscillations for language comprehension in the human electroencephalogram. Neuroscience Letters, 310, 137-140.

Ryu, J. J., \& Chaudhuri, A. (2007). Differences in attentional involvement underlying the perception of distinctive and typical faces. Perception, 36, 1057-1065.

Sauseng, P., Hoppe, J., Klimesch, W., Gerloff, C., \& Hummel, F. C. (2007). Dissociation of sustained attention from central executive functions: Local activity and interregional connectivity in the theta range. European Journal of Neuroscience, 25, 587-593.

Sederberg, P. B., Gauthier, L. V., Terushkin, V., Miller, J. F., Barnathan, J. A., \& Kahana, M. J. (2006). Oscillatory correlates of the primacy effect in episodic memory. Neuroimage, 32, 1422-1431.

Sederberg, P. B., Kahana, M. J., Howard, M. W., Donner, E. J., \& Madsen, J. R. (2003). Theta and gamma oscillations during encoding predict subsequent recall. Journal of Neuroscience, 23, 10809-10814.

Shah, A. S., Bressler, S. L., Knuth, K. H., Ding, M., Mehta, A. D., Ulbert, I., et al. (2004). Neural dynamics and fundamental mechanisms of event-related brain potentials. Cerebral Cortex, 14, 476-483.

Siapas, A. G., Lubenov, E. V., \& Wilson, M. A. (2005). Prefrontal phase locking to hippocampal theta oscillations. Neuron, 46, 141-151.

Singer, W., \& Gray, C. M. (1995). Visual feature integration and the temporal correlation hypothesis. Annual Review of Neuroscience, 18, 555-586.

Steriade, M., Gloor, P., Llinás, R. R., Lopes de Silva, F. H., \& Mesulam, M. M. (1990). Report of IFCN Committee on Basic Mechanisms. Basic mechanisms of cerebral rhythmic activities. Electroencephalography and Clinical Neurophysiology, 76, 481-508.

Tallon-Baudry, C., Bertrand, O., Delpuech, C., \& Permier, J. (1996). Stimulus specificity of phase-locked and non-phase locked $40 \mathrm{~Hz}$ visual responses in human. Journal of Neuroscience, 16, 4240-4249.

Tallon-Baudry, C., Bertrand, O., Delpuech, C., \& Permier, J. (1997). Oscillatory gamma-band 30-70 Hz. activity induced by a visual search task in humans. Journal of Neuroscience, 17, 722-734.

Tallon-Baudry, C., Bertrand, O., Hénaff, M. A., Isnard, J., \& Fischer, C. (2005). Attention modulates gamma-band oscillations differently in the human lateral occipital cortex and fusiform gyrus. Cerebral Cortex, 15, 654-662.

Tanaka, J. W. (2001). The entry point of face recognition: Evidence for face expertise. Journal of Experimental Psychology: General, 130, 534-543.

Trautner, P., Rosburg, T., Dietl, T., Fell, J., Korzyukov, O. A., Kurthen, M., et al. (2006). Sensory gating of auditory evoked and induced gamma band activity in intracranial recordings. Neuroimage, 32, 790-798.

Treves, A., \& Rolls, E. T. (1994). Computational analysis of the role of the hippocampus in memory. Hippocampus, 4, 374-391.

Tulving, E. (1983). Elements of episodic memory. New York: Oxford University Press. 
Tulving, E. (1995). Organization of memory: Quo vadis? In M. S. Gazzaniga (Ed.), The cognitive neurosciences (pp. 839-847). Cambridge, MA: MIT Press.

Vogt, F., Klimesch, W., \& Doppelmayr, M. (1998). High-frequency components in the alpha band and memory performance. Journal of Clinical Neurophysiology, 15, 167-172.

Von Stein, A., Chiang, C., \& König, P. (2000). Top-down processing mediated by interareal synchronization. Proceedings of the National Academy of Sciences, U.S.A., 97, 14748-14753.

Weiss, S., \& Rappelsberger, P. (2000). Long-range EEG synchronization during word encoding correlates with successful memory performance. Cognitive Brain Research, 9, 299-312.

Whitham, E. M., Lewis, T., Pope, K. J., Fitzgibbon, S. P., Clark, C. R., Loveless, S., et al. (2008). Thinking activates
EMG in scalp electrical recordings. Clinical Neurophysiology, 119, 1166-1175.

Yovel, G., \& Paller, K. A. (2004). The neural basis of the butcher-on-the-bus phenomenon: When a face seems familiar but is not remembered. Neuroimage, 21, 789-800.

Yuval-Greenberg, S., Tommer, O., Keren, A. S., Nelken, I., \& Deuoell, L. Y. (2008). Transient induced gamma-band response in EEG as a manifestation of miniature saccades. Neuron, 58, 429-441.

Zion-Golumbic, E., \& Bentin, S. (2007). Dissociated neural mechanisms for face detection and configural encoding: Evidence from N170 and induced gamma-band oscillation effects. Cerebral Cortex, 17, 1741-1749.

Zion-Golumbic, E., Golan, T., Anaki, D., \& Bentin, S. (2008). Human face preference in gamma-frequency EEG activity. Neuroimage, 39, 1980-1987. 